\title{
Dispersal of HIV positive asylum seekers: national survey of UK healthcare providers
}

\author{
S Creighton, G Sethi, S G Edwards, R Miller
}

\section{See also Education} and debate $\mathrm{p} 346$

Department of Genitourinary Medicine, Camden Primary Care Trust, Mortimer Market Centre, London WC1E $6 A U$

S Creighton consultant in genitourinar genitourinar

S G Edwards consultant in conitourinary medicine

Department of Departmen Genitourinary Medicine, St Mary's Hospital, London W2 1NY

\section{G Sethi} Centre for Sexual Research, Department of Population Sciences, Royal Free and University College Medical School, University College London, London

WC1E 6 AU

R Miller

reader in clinical infection

Correspondence to: S Creighton sarah.creighton@ camdenpct.nhs.uk

BMJ 2004;329:322-3 specialist registrar Health and HIV Primary Care and

In April 2000, the UK National Asylum Support Service started a policy of dispersing asylum seekers from London and southeast England to alternative locations around the United Kingdom in an attempt to spread the cost of care. ${ }^{1}$ Although the number of people with HIV who are affected by this policy is unknown, more than 100000 asylum seekers have so far been dispersed, many of whom are from regions with HIV/ AIDS epidemics. ${ }^{2}$ Asylum seekers may only receive 48 hours' notice, and, if they decline dispersal, then they face immediate cessation of income, housing, and legal support. Decisions about the dispersal of HIV positive asylum seekers should take into account expert medical and professional advice as dispersal may detrimentally affect the health of HIV positive asylum seekers. ${ }^{3}$ We asked doctors working in genitourinary medicine about their experiences and opinions of the dispersal of HIV positive asylum seekers.

\section{Participants, methods, and results}

We sent an anonymous questionnaire (see bmj.com) to all lead clinicians in English genitourinary medicine clinics in December 2003. We excluded centres which do not treat HIV infected patients. We contacted doctors who work at more than one site only once. The questionnaire asked about the doctor's experience of and opinion about the appropriateness of dispersal in 10 clinical scenarios and also about perceived barriers to effective dispersal (table). For each centre we recorded its location and the number of patients dispersed.

Of 75 eligible centres, 56 returned questionnaires; 34 of these were outside London and a third (20) had had an HIV infected asylum seeker dispersed to them. A total of 13 centres had had patients dispersed both to and from them. Of those who did not respond, 15/19 were from outside London. Thirty six centres had no experience of dispersal.

Of the 56 returned questionnaires, often cited barriers to successful dispersal were dispersal at short notice (37) or with no prior arrangement (43). Only

Responses to the statement "Dispersal of HIV positive persons of insecure immigration status is safe and appropriate in the following situations" from 56 lead doctors at English genitourinary clinics

\begin{tabular}{lccc} 
Situation & Disagree & Neither & Agree \\
\hline Recent psychosocial trauma & 46 & 8 & 2 \\
\hline Currently under medical investigation & 50 & 5 & 1 \\
\hline $\begin{array}{l}\text { Treatment from multiple medical specialties (eg hepatologists, surgeons, } \\
\text { other medical specialties) }\end{array}$ & 52 & 2 & 2 \\
\hline Current or recent AIDS diagnosis & 45 & 6 & 5 \\
\hline About to start antiretroviral therapy & 44 & 5 & 7 \\
\hline On antiretroviral therapy for <3 months & 47 & 6 & 3 \\
\hline Salvage antiretroviral therapy (in cases with resistance to antiretroviral therapy) & 43 & 9 & 4 \\
\hline Current or potential complications of antiretroviral therapy & 52 & 1 & 3 \\
\hline Never received antiretroviral therapy & 17 & 21 & 18 \\
\hline Asymptomatic HIV disease & 15 & 18 & 23 \\
\hline
\end{tabular}

\section{What is already known on this topic}

The UK policy of dispersal of asylum seekers, sometimes at short notice, leads to increase in HIV positive cases in some receiving centres

\section{What this study adds}

Most doctors who treat HIV positive asylum seekers have unsuccessfully contested dispersal

Doctors believe that dispersal is disruptive, may compromise HIV care, and may lead to increased transmission

three centres had experienced appropriate transfer of care. Other barriers included lack of community support (41), lack of facilities to support vulnerable asylum seekers with psychological problems (43), and low staffing levels in the receiving centre (40).

Although the questionnaire did not ask for specific negative consequences attributable to dispersal, some doctors added spontaneous comments. These included problems relating to unintentional interruption to antiretroviral therapy (4), mother to child transmission of HIV infection (3), and HIV related death (2). Of 33 centres reporting experience of patients being dispersed away from their service, 19 had experience of dispersal against medical advice.

Many of the 56 doctors felt that dispersal of HIV infected asylum seekers was inappropriate in specific situations-during initiation of antiretroviral therapy (47), in patients receiving salvage treatment (43), in those currently undergoing medical investigations (50), where care involved multiple medical specialties (52), and in those with AIDS (45).

\section{Comment}

We identified several potential barriers to the safe dispersal of HIV infected asylum seekers. Of particular concern is that dispersal is done at short notice and often without appropriate transfer of medical details. Although hand held medical records have been suggested as a potential solution, ${ }^{4}$ they are unlikely to resolve all the issues that could compromise patient care. Inappropriate dispersal of an HIV infected patient could lead to HIV resistance, onward transmission of HIV infection, and avoidable morbidity and mortality for the asylum seeker. Before the decision to disperse, the National Asylum Support Service should seek specialist advice and consider the impact on the infrastructure and staffing of the receiving centre.

The questionnaire is on bmj.com

This article was posted on bmi.com on 26 July 2004: http://bmj.com/cgi/ doi/10.1136/bmj.38189.674213.79 
This study is a reflection of doctors' opinions and is subject to reporting bias. However, the serious concerns raised warrant further investigation if we are to ensure that dispersal is not to be detrimental to patients' health.

Contributors: SC distributed and analysed the questionnaires and with RM wrote the first and last drafts. SGE conceived the study and with GS provided critical appraisal of the manuscripts. GS helped distribute the questionnaires. SC is guarantor.

Funding: None.

Competing interests: RM edits Sexually Transmitted Infections.

Ethical approval: Not needed.
1 Immigration and Asylum Act 1999. London: Stationery Office, 1999. www.legislation.hmso.gov.uk/acts/acts1999/19990033.htm (accessed 21 July 2003).

2 Health T, Jeffries R, Lloyd A. Asylum statistics in the United Kingdom. London: Home Office, 2003. wwwhomeoffice.gov.uk/rds/pdfs2/ hosb803.pdf (accessed 21 Jul 2004)

3 All Party Parliamentary Group on AIDS Migration and HIV. Improving lives in Britain. wwwappg-aids org.uk/Publications/Migration $\% 20$ and $\% 20$ HIV\%20Improving $\% 20$ Lives.pdf (accessed 21 July 2003).

4 Johnson RD. Asylum seekers in dispersal: healthcare issues. London: Home Office, 2003. www.homeoffice.gov.uk/rds/pdfs2/rdsolr1303.pdf (accessed 21 July 2003).

(Accepted 19 July 2004)

doi $10.1136 /$ bmj.38189.674213.79

\title{
DRUG POINTS
}

\section{Acquired haemophilia A may be associated with clopidogrel}

\author{
Montaser Haj, H Dasani, S Kundu, U Mohite, P W Collins
}

Acquired haemophilia $\mathrm{A}$ is a rare bleeding disorder caused by autoantibodies against factor VIII. ${ }^{1}$ Bleeding is often severe and may be life threatening. In half of patients, no underlying disorder is found, however, common associations are with autoimmune disease, malignancy, dermatological disorders, pregnancy, and drugs. ${ }^{1-3}$

Two women aged 70 and 67 presented with a history of excessive bruising and soft tissue bleeding 2-3 months after starting clopidogrel (Plavix; Bristol-Myers Squibb, Sanofi-Synthelabo) for peripheral vascular disease. Their drugs had not changed recently in any other way. They had no clinical symptoms or signs of malignancy, antiphosphpolipid syndrome, or collagen vascular disease.

One patient had had a documented normal activated partial thromboplastin time at the time of starting clopidogrel; the other had not been tested. Investigation showed that the women had a normal platelet count, peripheral blood film, and prothrombin time. Both had a prolonged activated partial thromboplastin time of 48.6 and 77.6 seconds (normal range 23-33 seconds). Tests for lupus anticoagulant, anticardiolipin antibody, antinuclear factor, double stranded DNA, and rheumatoid factor were negative. The women had low factor VIII (3.9 and 1 $\mathrm{IU} / \mathrm{dl}$ ) with normal von Willebrand factor levels and a detectable antifactor VIII inhibitor (2.2 and 17.6 Bethesda units). We treated both patients with $1 \mathrm{mg} / \mathrm{kg}$ of prednisolone. Concentrations of factor VIII rose to 119 and $136 \mathrm{IU} / \mathrm{dl}$, and the inhibitor became undetectable $(<0.4$ Bethesda units) within eight weeks of treatment. The factor VIII inhibitor relapsed in one patient when the steroid dose was reduced, but we induced and sustained remission with azathioprine.

A possible link between autoimmune acquired haemophilia and clopidogrel has not been previously reported. Clopidogrel has been associated with microangiopathic haemolytic anaemia and thrombocytopenia, ${ }^{45}$ suggesting other possible immune mediated adverse events.

Increased bruising should not be ascribed to the antiplatelet action of clopidogrel unless a platelet count and coagulation screen have been found to be normal. Investigation for an antifactor VIII inhibitor should be done if indicated by a prolonged activated partial thromboplastin time.

Funding: None.

Competing interests: None declared.

1 Green D, Lechner K. A survey of 215 non-hemophilic patients with inhibitors to factor VIII. Thromb Haemostas 1981;45:200-3. 2 Hay CRM. Acquired haemophilia. In: Bailliere's clinical haematology. London: Bailliere Tindall, 1998:287-303.

3 Morrison AE, Ludlam CA. Acquired haemophilia and its management. Br J Haematol 1995;89:231-6.

4 Bennett CL, Connors JM, Carwile JM, Moake JL, Bell WR, Tarantolo SR, et al. Thrombotic thrombocytopenic purpura associated with clopidogrel. $N$ Engl J Med 2000;342:1773-7.

5 Elmi F, Peacock T, Schiavone J. Isolated profound thrombocytopenia associated with clopidogrel. J Invas Cardiol 2000;12:532-5.

\section{Corrections and clarifications}

Variations and increase in use of statins across Europe: data from administrative databases

The authors of this paper, Tom Walley and colleagues, have alerted us to some errors in the data in their table (BMJ 2004;328:385-6). For Ireland, the total use of cerivastatin is in fact 0.416 (not 4.16) million defined daily doses (DDDs); this change affects the overall use of statins in Ireland, which becomes 11.06 (not 14.80) million DDDs a year. The value for DDDs per 1000 head of population in Italy is correct as stated. For France, the total use of atorvastatin is 236.58 (not 357.52) million DDDs, and the value for DDDs per head of population is 15.58 (not 23.56); these changes affect France's overall use of statins and its overall rate of use - these values become 730.46 (not 846.88) million DDDs and 48.11 (55.82) DDDs per head of population respectively.

\section{Administering, analysing, and reporting your} questionnaire

Readers may have been confused by the page reference given for reference 2 in this article by Petra M Boynton in the Hands-on Guide to Questionnaire Research series (5 June, pp 1372-5). The correct page reference is 573 .

Infertility among male UK veterans of the 1990-1 Gulf war: reproductive cohort study

An error in the text of the full version of this paper (http://bmj.bmjjournals.com/cgi/content/full/ $329 / 7459 / 196)$ by Noreen Maconochie and colleagues persisted until publication (24 July, pp 196-200). The odds ratio for an association of Gulf war service with a general diagnosis of type I male factor infertility should have been $1.16(95 \%$ confidence interval 0.74 to 1.82 ), as correctly given in table 3 .
Department of Haematology, University Hospital of Wales, Cardiff CF14 4XN

Montaser Haj specialist registrar in haematology

H Dasani associate specialist in haematology

S Kundu

specialist registrar in haematology

U Mohite specialist registrar in haematology

P W Collins senior lecturer in haematology

Correspondence to: P W Collins peter.collins@ cardiffandvale.wales. nhs.uk

BMJ 2004;329:323 